\title{
A COMPARATIVE STUDY OF EFFICACY AND SAFETY OF DICLOFENAC AND ACECLOFENAC IN THE TREATMENT OF OSTEOARTHRITIS PATIENTS
}

\author{
Patil Pramod Reddy*, Jaida Jyothirmai, Palani Anuradha, B Anandam, Rao Koteshwar
}

Department of Pharmacology, Prathima Institute of Medical Sciences, Nagunur road, Karimnagar, Andhrapradesh, India

*Corresponding Author's e-mail: pramod_patil85@rediffmail.com

Received 28 May 2012; Review Completed 29 June 2012; Accepted 29 June 2012, Available online 15 July 2012

\begin{abstract}
ABS TRACT:
Objectives: Osteoarthritis is a slowly evolving, active disease of degeneration of the articular cartilage associated with symptoms of joint pain, stiffness and limitation of movement. Typically, these symptoms tend to worse with weight bearing and activity. Non-steroidal anti-inflammatory drugs play an important role in the management of osteoarthritis. This study was conducted to compare efficacy and safety of Aceclofenac and Diclofenac in the treatment of osteoarthritis patient. Design: Randomized, single blinded, parallel group clinical study. Intervention: The study was conducted in 140 patients of OA. After initial clinical assessment and baseline investigations, Aceclofenac was prescribed to 70 patients and Diclofenac to another 70 patients for 8 weeks. At follow-up, the patients were re-evaluated and compared statistically. Main outcome measures: were Western Ontario MacMaster (WOMAC) scores, time taken to walk 100 feet, visual analogue scores for pain, investigators assessment for disease status and response to therapy, patient response to drug and joint tenderness. Safety assessment was based on adverse events. Results: Aceclofenac significantly improved patient's clinical condition from baseline to day 56 . Aceclofenac was found to be superior to Diclofenac in efficacy parameters of WOMAC osteoarthritis index scores $(\mathrm{p}<0.0001)$, joint tenderness $(p<0.0001)$, investigator assessment for disease status $(p=0.01)$ and response to therapy $(p=0.038), p$ atient response to drug $(\mathrm{p}=0.024)$. Aceclofenac and Diclofen ac were equally effective in other efficacy parameters. Aceclofenac was found well tolerated than Diclofenac in terms of epigastric discomfort, dy spepsia and abdominal pain. Conclusion: Aceclofenac is a better choice in osteoarthritis in comparison to Diclofenac due to its better efficacy and safety.

Keywords: Non Steroidal Anti-inflammatory Drugs, Visual Analogue Scale, WOMAC Osteoarthritis Index.
\end{abstract}

\section{INTRODUCTION:}

Osteoarthritis (OA) is one of the most common form of joint disease in humans and is a leading cause of musculoskeletal disability in elderly patients . The World Health Organization (WHO) figures of worldwide estimates are that $9.6 \%$ of men and $18 \%$ of women aged more than 60 years have symptomatic OA ${ }^{2}$

Combination of orally administered Non-steroidal antiinflammatory drugs and non pharmacological intervention play an important role in the symptomatic management of osteoarthritis. The ideal agent should have good efficacy and low propensity to cause adverse effects.

While NSA IDs are effective in the management of pain and inflammation in a large number of conditions including osteoarthritis, it is now well established that they are associated with development of upper gastrointestinal damage, including mucosal erosions, ulcers and life threatening conditions like perforation and hemorrhage. This led to the development of cyclo-oxygenase-2 inhibitors. The potential advantage of COX-2 inhibitor is that they have fewer adverse effects on the gastrointestinal tract as a result of having less inhibitory effect on the gastro-protective prostanoids produced by COX-1 en zy me in the gastrointestinal tract. This advantage of COX-2 selective NSAIDs has been demonstrated in many trials. ${ }^{3-5}$ However the cardiovascular safety of these drugs was found to be controversial. Three independent randomized trials and a cumulative meta-analysis confirmed excess cardiovascular risk as well as serious skin reactions were also seen with rofeco xib and valdeco xib. ${ }^{6,7}$

Diclofenac is an already established Non-steroidal antiinflammatory drug with analgesic and antipyretic properties. Diclofenac inhibits cyclo-oxygenase activity with reduction in the tis sue production of prostaglandins. It reduces joint swelling and relieves pain so is used in the treatment of rheumatoid arthritis and osteoarthritis. But studies on Diclofenac has shown increased incidence of adverse effects like abdominal pain, dyspepsia, diarrhoea, heartburn and GI u lcer.

Aceclofenac is an effective analgesic and antiinflammatory agent; through these properties it provides greater symptomatic relief in a variety of painful conditions. ${ }^{8}$ It has also shown to exert effects on a variety of mediators of inflammation. The drug inhibits synthesis of inflammatory cytokines like interleukin (IL) $-1 \beta$ and tumor necrosis factor (TNF) and inhibits prostaglandin E2 (PGE2) production. The mode of action of Aceclofenac has been recently clarified in that the compound was shown to elicit preferential inhibition of COX-2 as a result of limited but sustained biotransformation to Diclofenac. ${ }^{9}$

The present study was carried out to evaluate the efficacy and Safety of Aceclofenac for the treatment of osteoarthritis compared to Diclofenac.

\section{MATERIALS AND METHODS:}

\section{Subjects:}

The study was conducted on 140 patients aged 40-60 years with a history, symptoms and signs of osteoarthritis, radiologically diagnosed with osteoarthritis of knee, minimum Western Ontario MacMaster (WOMAC) Index of 40, Visual Analogue scale (VAS) score of $4 \mathrm{~mm}$ with normal haematology, renal function test and liver function test values were recruited from the Orthopaedic outpatient 
Patil et al

Journal of Drug Deli very \& Therape utics; 2012, 2(4), 139-143

department of Prathima Institute of Medical Sciences, Karimnagar, AP, India. Patients suffering from other rheumatic disease, with significant concomitant illness (e.g. bleeding tendencies, cirrhosis, esophageal varices, hypersensitivity to NSAIDs, peptic ulcers and duodenal ulcers), pregnant women, lactating mothers, patient's who would require concomitant therapy with drugs (e.g. warfarin, aspirin, corticosteroids, ticlopidine, antiepileptics and fluconazole) and who have previously received Diclofenac and or Aceclofenac for treatment of os teoarthritis were excluded from the study.

\section{Study design:}

The present study is a randomized, single blinded, parallel group comparative clinical study between Diclofenac and Aceclofenac in osteoarthritis of knee. The study was approved by Institute Ethical Committee and procedures followed in this study are in accordance with the ethical standards laid down by ICMR's Ethical guidelines for biomedical research on human subjects (2006). A written informed consent was taken from all the patients included in the trial after explaining the patient's diagnosis, the nature and purpose of a proposed treatment, the risks and benefits of a proposed treatment (Diclofenac/ Aceclofenac) and alternative treatment (Corticosteroids). After randomization by computer generated random numbers (done online: www.randomization.com), 140 patients who participated in the study were divided into two groups; 70 patients were assigned to receive Diclofenac $75 \mathrm{mg}$ twice daily and 70 patients received Aceclofenac 100mg twice daily for a period of 8 weeks. During the screening visit, information on their demographic characteristics, medical history and previous current medications was collected. A thorough physical examination and baseline laboratory investigations were carried out. At 8 weeks follow up, physical examination and baseline investigation were repeated and all post drug symptoms were recorded

\section{Efficacy measures:}

WOMAC Osteoarthritis Index was administered at both clinical visits, evaluating the following domains: pain, stiffness and difficulty performing daily activities using a battery of 24 questions. Every question was rated from 'none (0)', 'mild (1)', 'moderate (2)', 'severe (3)' and 'very severe (4)'.
Visual Analog Scale bypasses the cognitive level of brain and gives a true representation of pain. Symptom score for pain on $0-10 \mathrm{~mm}$ VAS was calculated for weight bearing, pain at rest and active movement

The patient was made to walk a distance of 100 feet and time taken was noted in seconds. The patient rated the overall response of his or her OA to study medications on a 0-4 Likert scale ('none', 'Poor', 'moderate', 'good', and 'excellent'). The investigator rated the overall assessment of disease status on a 0-4 Likert scale ('very poor', 'poor', 'moderate', 'well' and 'very well'). The investigator rated the response of the patient's OA to study medication on a 0-4 Likert scale ('none', 'Poor', 'moderate', 'good', and 'excellent'). Assessment of joint tenderness on 0-3 scale ('no pain ', 'pain', 'pain and wincing' and 'withdrawal').

\section{Safety measures:}

Safety was assessed on the basis of the adverse events reported, or by comparing the baseline symptoms with post-drug symptoms, or changes in vital signs, and physical examination findings recorded before and after the end of treatment. All reported adverse drug reactions were graded according to Common Toxicity Criteria (CTC) and compared between the groups.

\section{Statistical analysis:}

Statistical Package for Social Sciences (SPSS) version 17.0 software was used for analyzing results. Statistical test conducted were Paired t-test, Un-paired t-test, Pearson chi-square test and Fisher's exact test. Interval data have been expressed as Mean \pm SD. $\mathrm{P}$ value $<0.05$ was considered statistically significant.

\section{RES ULTS:}

In our study the two groups were homogenous with respect to baseline demographic data. At follow-up, 22 were lost and total 118 patients (60 in Aceclofenac group and 58 in Diclofenac group) completed the study. Among 140 patients, 86 patients $(61.42 \%)$ were female and 54 patients $(38.58 \%)$ were male. The mean age was $52.80 \pm 4.55$ years in Diclofenac group and $53.61 \pm 5.64$ years in Aceclofenac group.

Table 1: Change in WOMAC Osteoarthritis Index scores in study groups

\begin{tabular}{|c|c|c|c|c|c|c|c|}
\hline \multirow{3}{*}{ Variable } & \multicolumn{3}{|c|}{ Diclofenac group } & \multicolumn{3}{|c|}{ Aceclofenac group } & \multirow{3}{*}{$\begin{array}{c}\text { Difference } \\
\text { b/w groups } \\
\text { at } 2^{\text {nd }} \text { visit } \\
\Psi\end{array}$} \\
\hline & \multicolumn{2}{|c|}{ Visit } & \multirow{2}{*}{$\begin{array}{c}\text { P value } \\
\$\end{array}$} & \multicolumn{2}{|c|}{ Visit } & \multirow{2}{*}{$\begin{array}{c}P \text { value } \\
\$\end{array}$} & \\
\hline & $1^{\text {st }}$ & $2^{\text {nd }}$ & & $1^{\text {st }}$ & $2^{\text {nd }}$ & & \\
\hline $\begin{array}{l}\text { Pain questionnaire } \\
\text { scoring }\end{array}$ & $12.3 \pm 3.13$ & $8.76 \pm 1.09$ & $<0.0001$ & $12.0 \pm 1.08$ & $7.60 \pm 1.18$ & $<0.0001$ & $<0.0001$ \\
\hline $\begin{array}{l}\text { Stiffness questionnaire } \\
\text { scoring }\end{array}$ & $4.21 \pm 0.58$ & $3.26 \pm 0.76$ & $<0.0001$ & $4.17 \pm 0.61$ & $2.73 \pm 0.75$ & $<0.0001$ & $<0.0001$ \\
\hline $\begin{array}{l}\text { Difficulty performing } \\
\text { daily activ ities } \\
\text { questionnaire scoring }\end{array}$ & $39.91 \pm 2.14$ & $30.66 \pm 1.78$ & $<0.0001$ & $40.67 \pm 2.17$ & $29.03 \pm 2.06$ & $<0.0001$ & $<0.0001$ \\
\hline $\begin{array}{l}\text { WOMAC score } \\
\text { (overall) }\end{array}$ & $56.48 \pm 3.59$ & $42.67 \pm 1.99$ & $<0.0001$ & $56.83 \pm 2.31$ & $38.0 \pm 2.29$ & $<0.0001$ & $<0.0001$ \\
\hline
\end{tabular}

Data are in Mean $\pm \mathrm{SD}, \$=$ Paired t-test,$\Psi=$ Un pai re d t-test 
Excluded

- Not meeting inclusion criteria $(\mathrm{n}=15)$

- Declined to participate $(\mathrm{n}=5)$

Enrollment

- Other reas ons $(\mathrm{n}=0)$

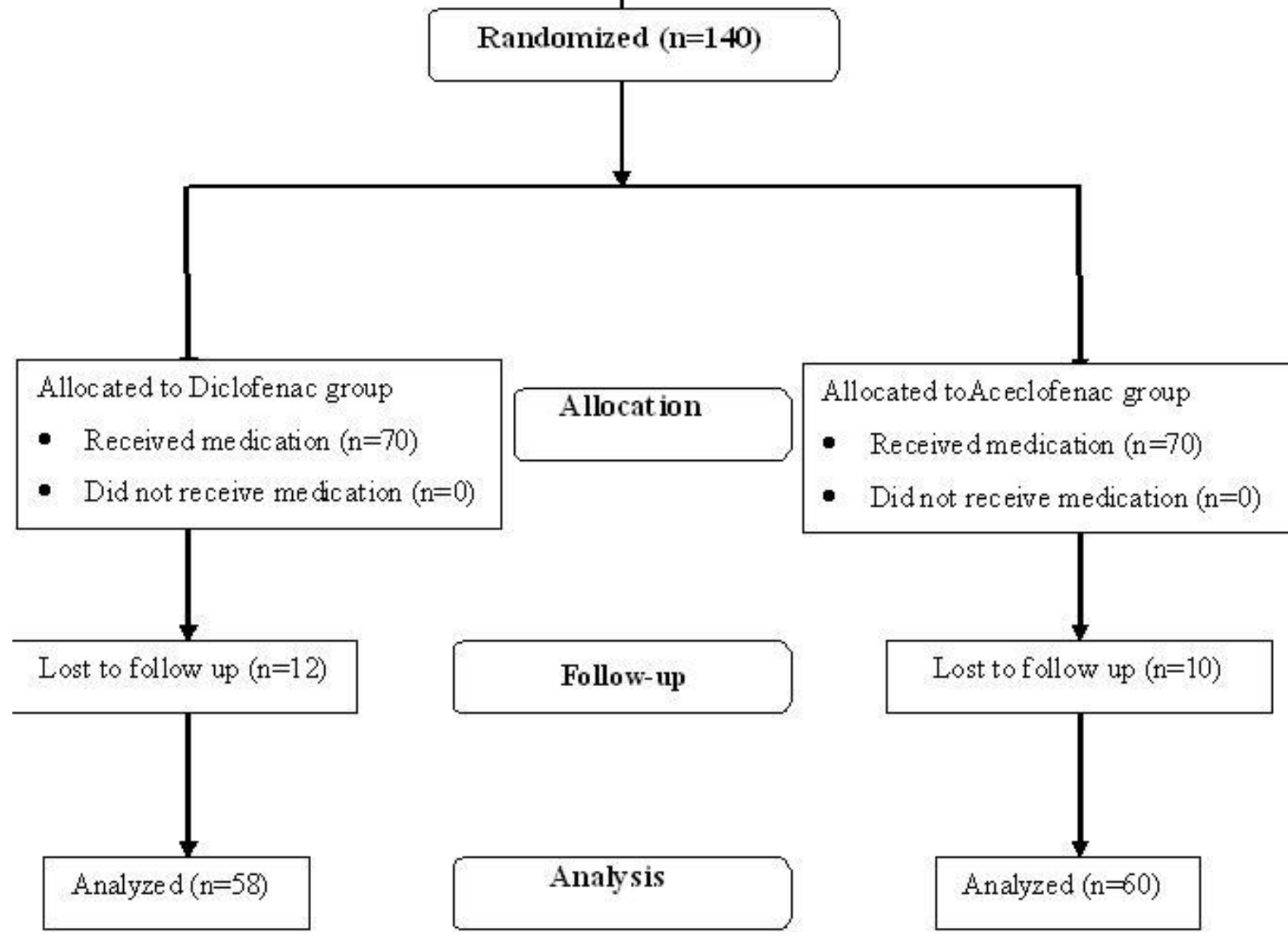

Figure 1: Participant flow through the study

Table 2: Change in Visual Anal ogue scale scores for pain in study groups.

\begin{tabular}{|c|c|c|c|c|c|c|c|}
\hline \multirow{3}{*}{ Variable } & \multicolumn{3}{|c|}{ Diclofenac group } & \multicolumn{3}{|c|}{ Aceclofenac group } & \multirow{3}{*}{$\begin{array}{c}\text { Difference } \\
\text { b/w groups } \\
\text { at } 2^{\text {nd }} \text { visit } \\
\Psi\end{array}$} \\
\hline & \multicolumn{2}{|c|}{ Visit } & \multirow{2}{*}{$\begin{array}{c}\text { P value } \\
\$\end{array}$} & \multicolumn{2}{|c|}{ Visit } & \multirow{2}{*}{$\begin{array}{c}\text { P value } \\
\$\end{array}$} & \\
\hline & $1^{\mathrm{st}}$ & $2^{\text {nd }}$ & & $1^{\text {st }}$ & $2^{\text {nd }}$ & & \\
\hline During weight bearing & $5.29 \pm 0.95$ & $2.88 \pm 1.09$ & $<0.0001$ & $5.30 \pm 0.83$ & $2.77 \pm 0.92$ & $<0.0001$ & 0.547 \\
\hline At rest & $4.72 \pm 0.93$ & $2.71 \pm 1.02$ & $<0.0001$ & $4.83 \pm 1.02$ & $2.38 \pm 0.84$ & $<0.0001$ & 0.064 \\
\hline $\begin{array}{l}\text { During active } \\
\text { movement }\end{array}$ & $5.40 \pm 0.93$ & $3.65 \pm 1.25$ & $<0.0001$ & $5.20 \pm 0.86$ & $2.87 \pm 1.21$ & $<0.0001$ & 0.207 \\
\hline
\end{tabular}

Data are in Mean $\pm \mathrm{SD}, \$=$ Paire d t-test, $\Psi=$ Unpai red t-test

The changes in WOMAC osteoarthritis index scores, joint tenderness score, investigators assessment of disease status score and response to therapy and patient's response to drug in both Diclofenac and Aceclofenac groups were statistically significant by paired t-test and when the same parameters were compared at $2^{\text {nd }}$ visit between Diclofenac and Aceclofenac groups by unpaired t-test, there was significant difference between the groups. Both Aceclofenac and Diclofenac were equally effective in significantly reducing VAS pain score during weight bearing, at rest and during active movement, and also time taken to walk 100 feet distance. In our study all the 
Patil et al

Journal of Drug Deli very \& Therape utics; 2012, 2(4), 139-143

reported side effects were of grade 1 (mild), according to CTC grading of adverse drug reactions. No clinically significant post-treatment changes were observed in haematology, renal function test and liver function test in any of the patients. The overall incidence of adverse effects was $29.4 \%$ in Diclofenac group and $11.7 \%$ in Aceclofenac group. To compare the incidence of adverse effects of two groups Fischer's Exact test was done and it was found to be statistically significant in Diclofenac $\operatorname{group}(\mathrm{p}=0.02)$.

Table 3: Change in efficacy measures in study groups.

\begin{tabular}{|c|c|c|c|c|c|c|c|}
\hline \multirow{3}{*}{ Variable } & \multicolumn{3}{|c|}{ Diclofenac group } & \multicolumn{3}{|c|}{ Aceclofenac group } & \multirow{3}{*}{$\begin{array}{c}\text { Difference } \\
\text { b/w groups } \\
\text { at } 2^{\text {nd }} \text { visit } \\
\Psi\end{array}$} \\
\hline & \multicolumn{2}{|c|}{ Visit } & \multirow{2}{*}{$\begin{array}{c}\text { P value } \\
\$\end{array}$} & \multicolumn{2}{|c|}{ Visit } & \multirow{2}{*}{$\begin{array}{c}\text { P value } \\
\$\end{array}$} & \\
\hline & $1^{\text {st }}$ & $2^{\text {nd }}$ & & $1^{\text {st }}$ & $2^{\text {nd }}$ & & \\
\hline $\begin{array}{l}\text { Time taken to walk } \\
100 \mathrm{ft}\end{array}$ & $102 \pm 3.59$ & $84.93 \pm 9.02$ & $<0.0001$ & $101.45 \pm 11.65$ & $82.88 \pm 9.35$ & $<0.0001$ & 0.230 \\
\hline $\begin{array}{l}\text { Joint tenderness } \\
\text { score }\end{array}$ & $1.48 \pm 1.06$ & $0.81 \pm 0.57$ & $<0.0001$ & $1.58 \pm 0.94$ & $0.53 \pm 0.50$ & $<0.0001$ & 0.006 \\
\hline Disease status score & $2.36 \pm 0.66$ & $2.52 \pm 0.62$ & 0.028 & $2.20 \pm 0.65$ & $2.82 \pm 0.62$ & $<0.0001$ & 0.011 \\
\hline
\end{tabular}

Data are in Mean \pm SD, $\$=$ Pai re d t-test, $\Psi=$ Unpai red t-test

Table 4: Assessment of res ponse to drug

\begin{tabular}{|l|c|c|c|}
\hline Variable & Diclofenac group & Aceclofe nac group & $\Psi$ P value \\
\hline By Investigator & $2.36 \pm 1.07$ & $2.75 \pm 0.93$ & 0.038 \\
\hline By Patient & $2.19 \pm 0.60$ & $2.47 \pm 0.70$ & 0.024 \\
\hline
\end{tabular}

Data are in Mean $\pm S D, \Psi=$ Un pai red t-test

\section{DISCUSS ION:}

Treating the symptoms of osteoarthritis and ensuring a decent quality of life to the patients is challenging to the physician. Increasing understanding of the pathophysiological mechanism in the last few decades have revealed the use of different NSAIDS in the treat ment of osteoarthritis.

In our study improvement was seen in all three domains and overall WOMAC osteoarthritis index with both the drugs. But the improvement with Aceclofenac was found to be better in comparison to Diclofenac. The findings of our study are similar to that of the previous studies done by Pareek A et al 2006. ${ }^{10}$ Both the drugs are almost equally effective in reducing pain score during weight bearing, at rest and on active movement by visual analogue scale. Our results are comparable with the study done by Pareek A et al 2006 and Ward DE et al 1995. ${ }^{10,} 11$ In our study Aceclofenac is superior to Diclofenac in decreasing joint tenderness score similar to previous studies by Pareek A et al 2006 and Ward DE et al 1995. ${ }^{10,11}$ Aceclofenac was better than Diclofenac in improving the disease and investigator response to therapy, which is supported by previous studies done by Ward DE et al 1995. ${ }^{11}$ Patient response to Aceclofenac was better than Diclofenac which is supported by previous studies done by Ward DE et al 1995, Wassif et al 1992, Accardo $S$ et al 1995. ${ }^{11-13}$ The superiority of Aceclofenac in our study may be attributed to its stimulatory effect on cartilage matrix synthesis by inhibiting IL- $\beta$. There is evidence that Aceclofenac stimulates the synthesis of $\mathrm{IL}-1$ receptor antagonist in human articular chondrocyte subjected to inflammatory stimuli $^{14}$ and that 4-hydroxyaceclofenac has chondroprotective properties attributed to suppression of IL-1 $\beta$ mediated promatrix metalloproteinase production and proteoglycan release. ${ }^{15,16}$ In vitro data has shown that, there is stimulation of glycosaminoglycan synthesis in human osteoarthritic cartilage by Aceclofenac. The antiinflammatory effects of Aceclofenac have been shown due to inhibition of various mediators like IL-1 $\beta$, IL-6 and tumor necrosis factor in human osteoarthritic synovial cells and human articular chondrocytes, inhibition of PGE2 via cyclooxygenase inhibition (COX-1 \& COX-2) after intracellular metabolism to 4 hydroxy-aceclofenac and Diclofenac in human rheumatoid synovial cells and other inflammatory cells, inhibition of Reactive oxygen species, expression of cell adhesion molecules has also been shown in human neutrophils. The overall incidence of adverse effects in our study was $29.4 \%$ in Diclofenac and $11.7 \%$ in Aceclofenac group. Aceclofenac was well tolerated than Diclofenac in terms of epigastric discomfort, dyspepsia and abdominal pain. This is supported by previous study done by Pareek A et al 2006, Ward DE et al 1995, Wassif et al 1992 and Accardo S et al 1995. 10,11,12,13

\section{CONCLUSION:}

Analysis of results of all the parameters of safety and efficacy explores the probable superiority of Aceclofenac over Diclofenac in osteoarthritis. Because single blinding was a limitation, the findings of this study can be confirmed by multicentric, randomized, double blinded large population studies.

\section{ACKNOWLEDGEMENTS :}

The authors would like to thank V Sameer for his valuable suggestions, active help and encouragement. I am really grateful to Intas Pharmaceuticals Ltd, for supplying 3DVET (Diclofenac) and Hifenac (Aceclofenac) free of cost for the patients of our study group. 


\section{REFERENCES :}

1. Walker-bone k, Javaid K, Arden N, et al. Regular review: medical management of osteoarthritis. BJM 2000; 321:93640.

2. Murray CJL, Lopez Ad, eds. The global burden of disease. A comprehensive assessment of mortality and disability from diseases, injuries, and risk factors in 1990 and projected to 2020. Cambridge, MA: Harvard School of Public Health on behalf of the World Health Organisation and the World Bank; 1996.

3. Goldstein JL, Correa P, Zhao WW, et al. Reduced incidence of gastroduodenal ulcers with celecoxib, a novel cyclooxy genase- 2 inhibitors, compared to naproxen in patients with arthritis, Am J Gastroenterol 2001; 96:1019-27.

4. Laine L, Harper S, Simon T, et al. A randomized trial comparing the effect of rofecoxib, a novel cyclo-oxy genase-2 inhibitor, with that of ibuprofen on the gastroduodenal mucosa of patients with osteoarthritis. Refocoxib osteoarthritis Endoscopy Study group.Gastroenterology 1999; 117: 776-83

5. Hawakey C, Laine L, Simon T, et al.Comparision of the effect of rofecoxib, ibuprofen, and a placeboon the gastroduodenal mucosa of patients with osteoarthritis: a randomized, double blind, placebo controlled trial. The Rofecoxib osteoarthritis Endoscopy Multinational study group. Arthritis rheum 2000:43:370-7.

6. Juni P, Nartey, Reichenbach S, et al. Risk of cardiovascular events and rofecoxib, cumulative meta-analysis. Lancet 2004:364:2021-9.

7. Nussmeier NA, Whelton AA, Brown MT, et al Complications of COX-2 inhibitors parecoxib and valdecoxib after cardiac surgery.N Engl J Med 2005;352;1081-91.
8. Dooley M, Spencer CM, Dunn CJ. Aceclofenac: a reappraisal of its use in the management of pain and rheumatic disease. Drugs.2001:61:1351-78.

9. Hinz B, Brune K. Pain and osteoarthritis: new drugs and mechan isms. Curr op on rheumatol 2004; 16: 628-33.

10. Pareek A, Chandanwale AS, Oak J, Jain UK, Kapoor S. Efficacy and safety of aceclofenac in the treatment of osteoarthritis: a randomized double-blind comparative clinical trial versus diclofenac - an Indian experience. Curr Med Res Opin. 2006 May;22(5):977-88.

11. Ward DE, Veys EM, Bowdler JM, Roma J. Clinical rheumatology 1995 Nov volume 14, number 6,656-662.

12. Wassif, W.,Bjarnason,I. A conparision of the effects of aceclofenac and diclofenac on gastrointestinal blood loss, Br J Clin Res 1992,3.109-114.

13. Accardo S,Seriolo B, Tirri G, Colombo B, Fumagali M, Lotti G, Pagliara L, Parnham MJ, Alepuz M (1995) Long term safety profile of aceclofen ac in the treatment of articular pain. Eur J Rheumatol Inflam 15:35-41.

14. Maneiro, Lopez- Armada MJ, Fernandez-sueiro JL, et al. Aceclofenac incrases the synthesis of interleukin 1 receptor antagonist and decrease the production of nitric oxide I human articular chondrocyte. J rheumatol 2001; 28: 2692-9.

15. Akimoto H, Yamazaki R, Hashimoto S, et al. 4-Hydroxyaceclofenac suppresses the interleukin-1 induced production of promatrix metalloproteinases and release of sulfatedgly cosaminoglycans from rabbit articular chondrocyte. Eur $\mathbf{J}$ Pharmacol 2000; 401: 429-36.

16. Yamazaki R, Kawai S, Mizushima Y, et al. A major metabolite of aceclofenac, 4-hy roxy aceclofenac, suppresses the production of interstial pro-collagenase/ ProMMP-1 and prosto-mely sin-1/ ProMMP-3 by human rheumatoid synovial cells. Inflamm Res 2000; 49: 133-8. 